\title{
Autologous Hematopoietic Stem Cell Therapy of the Subjects with Systemic Sclerosis: Electromyographic Results of the Masticatory Muscles
}

Thamyres Branco', Ligia Franco Oliveira', Marcelo Palinkas ${ }^{1,2,3}$ Paulo Batista de Vasconcelos ${ }^{1}$, Maria Carolina Oliveira ${ }^{4}$, Belinda Pinto Simões ${ }^{4}$, Isabela Hallak Regalo', Selma Siéssere ${ }^{1,3}$, Simone Cecilio Hallak Regalo ${ }^{1,3}$

${ }^{1}$ School of Dentistry of Ribeirão Preto, University of São Paulo, São Paulo, Brazil; ${ }^{2}$ Faculty Anhanguera, Ribeirão Preto, São Paulo, Brazil;

${ }^{3}$ National Institute and Technology - Translational Medicine (INCT.TM), São Paulo, Brazil;

${ }^{4}$ School of Medicine, University of São Paulo, Ribeirão Preto, Brazil; Bone Marrow Transplantation Unit, Hospital das Clínicas, School of Medicine, University of São Paulo, Ribeirão Preto, Brazil

Received June 28, 2020; Accepted September 14, 2020.

Key words: Systemic sclerosis - Hematopoietic stem cell transplantation Electromyography - Masticatory muscles

Abstract: Musculoskeletal system impairment is a major cause of functional alterations in subjects with systemic sclerosis. Autologous hematopoietic stem cell therapy (AHSCT) may have an important role in the treatment functional of systemic sclerosis patients. The aim of this pilot study was to assess whether AHSCT interferes with the electromyographic activity of the masseter and temporalis muscles of subjects with systemic sclerosis. Before transplantation, seven subjects with systemic sclerosis (mean age [ \pm SD], $40.1 \pm 9.6$ years) underwent electromyographic analysis of the masseter and temporalis muscles in mandibular tasks at rest, right and left laterality, protrusion and maximum voluntary contraction. Two months after AHSCT, the subjects re-evaluated using the same methods.

This study was supported by the Ribeirão Preto School of Dentistry, University of São Paulo, State of São Paulo Research Foundation (FAPESP) and National Institute and Technology - Translational Medicine (INCT.TM).

Mailing Address: Prof. Marcelo Palinkas, PhD., School of Dentistry of Ribeirão Preto, University of São Paulo, Avenida do Café s/n, Bairro Monte Alegre CEP 14040-904, Ribeirão Preto, São Paulo, Brazil; e-mail: palinkas@usp.br 
Data were analyzed using the repeated-measure test, with $p<0.05$ considered to be statistically significant. Two months after AHSCT, there was reduction in normalized electromyographic activity in the dental clenching in maximal voluntary contraction, with significant differences, for the left temporal muscle $(p=0.04)$. AHSCT in subjects with systemic sclerosis promotes alterations in stomatognathic system function, especially those related to electromyographic activity of masticatory muscles.

\section{Introduction}

Systemic sclerosis is a complex, autoimmune, generalized connective tissue syndrome that presents with chronic fibrotic and inflammatory changes that cause skin tissue thickening and is characterized by microvascular lesions (Sierra-Sepúlveda et al., 2019; Perković et al., 2020). The main clinical signs of systemic sclerosis include limitation of skin movement, muscle pain, weakness, skin thickening, and peripheral vasoconstriction (Mirsaeidi et al., 2019; van Leeuwen et al., 2020).

The incidence of systemic sclerosis has increased over the past decade, although the one-year mortality rate has decreased slightly (Butt et al., 2018). In the United States, the prevalence for this uncommon condition is of approximately 20 persons per million in the general population (Bergamasco et al., 2019).

The disorder frequently involves the orofacial tissues (Crincoli et al., 2016), along with muscular atrophy that contributes to bone resorption compromising the temporomandibular joint, atrophy of the skin and face, hardening and loss of elasticity of the oral mucosa, and difficulties with swallowing and chewing (lordache et al., 2019; Mendonça et al., 2019).

Systemic sclerosis a multidisciplinary disease, as it involves many organs and systems, leading to wide range of symptoms and limitations. The treatment of this autoimmune disease remains a major challenge to the medical field and, as such, new therapeutic options are continually being sought (Sobolewski et al., 2019).

In the past 20 years, autologous hematopoietic stem cell transplantation (AHSCT) has emerged as a treatment option for patients with severe and progressive systemic sclerosis. Randomized studies have shown that transplantation is superior to conventional immunosuppressive treatment, promoting longer survival, better disease control and improved quality of life (van Laar et al., 2014; Sullivan et al., 2018).

Functional deterioration is associated with AHSCT (Wiskemann and Huber, 2008) and shortly after transplantation, patients are advised to reduce the amount of functional activity (Dimeo et al., 2003). However, this inactivity can have the opposite effect, impairing muscle function, so therapy is a promising treatment that restores muscle function, even in a short period of time (Plowman et al., 2014).

Thus, the aim of this pilot study was to evaluate electromyographic activity of the masticatory muscles, before and two months after selected subjects with systemic sclerosis underwent AHSCT. The null hypothesis was that autologous stem cell transplantation does influence the eleytomyographic activity of the masticatory muscles after two months of treatment in subjects with systemic sclerosis. 


\section{Material and Methods}

Study design

This study was approved by the Research Ethics Committee (protocol No. 94010718.4.00000.5419), based on Resolution 466/2012 of the Brazilian National Health. All procedures followed were in accordance with the ethical standards of the responsible committee on human experimentation (University of Sao Paulo, Brazil) and with the Helsinki Declaration of 1975, as revised in 2008. Informed consent was obtained from all subjects who participated in the study.

Sample size calculation was based on a study using $\mathrm{G}^{*}$ Power version 3.1.9.2 software (Franz Faul, Kiel University, Kiel, Germany), a priori considering $\alpha=0.05$, an effect size of 1.41 , and a test power of $87 \%$ for the main result of EMG (electromyography) activity in subjects with systemic sclerosis (HausmanowaPetrusewicz et al., 1982). The minimum sample size obtained was seven.

In this prospective, longitudinal study, recruitment and selection of subjects were performed by open invitation of systemic sclerosis patients treated at the University Hospital of the Ribeirão Preto Medical School, Brazil. All subjects had a confirmed diagnosis of systemic sclerosis according to the 2013 American College of Rheumatology/European League Against Rheumatism criteria (Johnson, 2015) and fulfilled previously published (Burt et al., 2013) indications for AHSCT. All subjects were assessed by a questionnaire that determined the presence or absence of temporomandibular dysfunction according to the Research Diagnostic Criteria for Temporomandibular Disorders (RDC/TMD). Dental evaluation was performed using anamnesis and a clinical form.

At the beginning of this study, 20 subjects with natural dentition were evaluated for the presence of first permanent molars, and for normal occlusion without temporomandibular dysfunction. Subjects for whom AHSCT was denied due to exclusion criteria for transplantation (Burt et al., 2011) were ineligible for the present study. Furthermore, subjects with ulceration(s), open wounds or skin hypersensitivity, cognitive impairment, neurological and/or systemic (decompensated) disorders, edentulous, use of full or removable prosthesis, periodontal disease, parafunctional habits, mandibular torus and/or palatine, and those using muscle relaxants that could interfere with neuromuscular physiology were excluded.

Ten systemic sclerosis patients were included in the present study. However, three subjects died between the initial analysis and the two months after therapy time point. Therefore, seven subjects participated in the study (mean age [ $\pm \mathrm{SD}], 40.1 \pm 9.6$ years). They initially underwent electromyographic analysis of the masseter and temporalis muscles. Two months after treatment, these seven subjects with systemic sclerosis were re-evaluated with the same methods.

Evaluation of electromyographic activity was performed by a single trained professional. Intra-examiner calibration was performed for all analyses in this study. 
Hematopoietic stem cell collection

Transplant procedure has been previously published (Burt et al., 2011). Briefly, stem cells were mobilized from the bone marrow to the peripheral blood with intravenous cyclophosphamide, followed by granulocyte colony growth factor (G-CSF) injections (van Laar et al., 2014). Stem cell collection was performed by leukapheresis; unselected cells were cryopreserved (Blank et al., 2016).

Pre-transplant preparation included high doses of cyclophosphamide and antithymocyte globulin, aiming to ablate the immune system and eliminate autoreactive cells. Then, the hematopoietic and immune systems were restored through infusion of the previously harvested autologous hematopoietic stem cells.

\section{Electromyographic analysis}

Electromyographic activity of the masseter and temporalis muscles, reflected by the patterns of muscle fiber activation, was recorded using a wireless system (Trigno, Delsys Inc., Boston, MA, USA).

The sensors were positioned on the subjects by the same operator trained and trained according to the Surface ElectroMyoGraphy for the Non-Invasive Assessment of Muscles (SENIAM) recommendations (Hermens et al., 2000). Dental clenching manoeuvres in maximal voluntary contraction were performed to establish the optimal collection points for electromyographic signals of the masseter and temporalis muscles (Cecílio et al., 2010).

Electromyographic signal data, in microvolts/s, were calculated using the square mean root for mandibular tasks. The skin was sanitized with alcohol to decrease impedance and the sensors were fixed after a few minutes of this procedure (Di Palma et al., 2017).

Electromyographic signal recording adhered to the following protocol for mandibular tasks: rest (4s); right (4s) and left (4 s); laterality, protrusion (4 s); and dental clenching in maximal voluntary contraction with (4s) and without (4s) inert material.

The inert material consisted of a 12-folded paraffin sheet (Parafilm M, Pechinery Plastic Packaging, Batavia, IL, USA) $(18 \times 17 \times 4 \mathrm{~mm}$, weight $245 \mathrm{mg})$ and inserted between the occlusal faces of the first permanent molars, on both the right and left sides of the dental arch (Siéssere et al., 2009).

\section{Statistical analysis}

In the analysis of the results, the data showed normal distribution (ShapiroWilk normality test: $\mathrm{p}<0.05)$. The electromyographic values for the masseter and temporalis muscles were normalized with respect to the electromyographic amplitude values obtained from each muscle during a maximal voluntary clench on Parafilm M. Statistical analysis of normalized electromyographic data was performed using SPSS version 22.0 (IBM Corporation, Armonk, NY, USA) for Windows 
(Microsoft Corporation, Redmond, WA, USA). The data were analyzed using a repeated measure test. Statistical significance was set at the level of $p<0.05$.

\section{Results}

Table 1 shows the normalized electromyographic data from the masseter and temporalis muscles at rest and under mandible postural conditions before and after AHSCT in systemic sclerosis subjects. Lower normalized electromyographic activity was observed in the dental clenching in maximal voluntary contraction of the left temporal muscle $(p=0.04)$, when compared to baseline (pre-therapy) measurements.

\section{Table 1 - Normalized electromyographic data and mean \pm standard error of the right masseter (RM), left masseter (LM), right temporal (RT) and left temporal (LT) muscles in the mandibular tasks of subjects with systemic sclerosis before (GI) and after (GII) autologous hematopoietic stem cell therapy (AHSCT)}

\begin{tabular}{lccc}
\hline Variable & GI & GII & p-value \\
\hline Total sample size & 07 & 07 & NA \\
\hline Variables - muscle & & & \\
\hline Rest - RM & $0.25 \pm 0.10$ & $0.19 \pm 0.10$ & NS \\
Rest - LM & $0.29 \pm 0.12$ & $0.20 \pm 0.07$ & NS \\
Rest - RT & $0.47 \pm 0.16$ & $0.18 \pm 0.03$ & NS \\
Rest - LT & $0.29 \pm 0.06$ & $0.26 \pm 0.08$ & NS \\
\hline Right laterality - RM & $0.59 \pm 0.23$ & $0.29 \pm 0.11$ & NS \\
Right laterality - LM & $0.53 \pm 0.19$ & $0.32 \pm 0.10$ & NS \\
Right laterality - RT & $0.46 \pm 0.18$ & $0.18 \pm 0.04$ & NS \\
Right laterality - LT & $0.30 \pm 0.10$ & $0.19 \pm 0.06$ & NS \\
\hline Left laterality - RM & $0.48 \pm 0.18$ & $0.20 \pm 0.08$ & NS \\
Left laterality - LM & $0.41 \pm 0.17$ & $0.19 \pm 0.04$ & NS \\
Left laterality - RT & $0.65 \pm 0.24$ & $0.26 \pm 0.11$ & NS \\
Left laterality - LT & $0.24 \pm 0.06$ & $0.21 \pm 0.09$ & NS \\
\hline Protrusion - RM & $0.62 \pm 0.26$ & $0.14 \pm 0.03$ & NS \\
Protrusion - LM & $0.29 \pm 0.14$ & $0.23 \pm 0.08$ & NS \\
Protrusion - RT & $0.35 \pm 0.16$ & $0.14 \pm 0.02$ & NS \\
Protrusion - LT & $0.31 \pm 0.08$ & $0.23 \pm 0.07$ & NS \\
\hline Dental clenching - RM & $1.02 \pm 0.14$ & $0.82 \pm 0.09$ & NS \\
Dental clenching - LM & $1.05 \pm 0.13$ & $0.85 \pm 0.11$ & NS \\
Dental clenching - RT & $0.93 \pm 0.07$ & $0.80 \pm 0.06$ & NS \\
Dental clenching - LT & $1.02 \pm 0.16$ & $0.73 \pm 0.08$ & $0.04 *$ \\
\hline
\end{tabular}

*significant difference, repeated-measure test (i.e. $\mathrm{p}<0.05$ ); NA - not applicable (paired samples); NS - not significant 


\section{Discussion}

The null hypothesis of this study was rejected by the positive influence of therapy according to electromyographic activity of the masseter and temporalis muscles in subjects with systemic sclerosis.

AHSCT in patients with systemic sclerosis induces the production of new cells from the immune and hematopoietic systems, for the purpose of eliminating autoreactivity and, as consequence, recovering the patient's general health (Lee et al., 2016). Skeletal muscles are involved in this autoimmune disease (Costa-Pereira et al., 2019), however, little is known about how masticatory muscles behave in the context of systemic sclerosis.

The involvement of striated skeletal muscles in subjects with systemic sclerosis is a consequence of ischemic, inflammatory, and sclerotic processes due to oxygenation and insufficient nutrition of the muscular tissue (Giudice et al., 2018). After AHSCT, there is a noteworthy increase in the quantity of blood vessels, which in turn improves peripheral and visceral blood circulation, and decreases in the activity of inflammatory processes (Khodayari et al., 2019). These factors may be related to reduced myoelectric activity due to increased blood flow in muscle tissue, promoting lower intramuscular pressures and, in consequence, functional improvement (McNeil et al., 2015).

Two months after transplantation, a reduction in normalized electromyographic activity of the temporal muscle in the dental clenching in maximal voluntary contraction was observed. Importantly, the most active muscle in this neuroanatomical movement is the masseter, which has a very rich arterial supply (Hwang et al., 2001). It is well known in the medical field that subjects treated with AHSCT exhibit more active patterns in organizing vascular architecture, with microcapillary regeneration (Miniati et al., 2009). We therefore believe that these functional outcomes may be related to an enriched balance and reduced electromyographic activity of the masticatory muscles due to microvascular tissue remodelling, increased tissue oxygenation, and improved muscle performance.

Another hypothesis to explain the reduction in electromyographic activity in the postural condition of dental clenching in maximum voluntary contraction would be that the muscle involvement through electromyographic evaluation of subjects with systemic sclerosis may be related to the formation of mandibular osteolysis that promotes imbalance(s) in electromyographic activity (Maiti et al., 2018). The transplantation could promote osteometabolic regeneration of the mandible, with reduction in bone ischemia and in muscle tissue pressure over the mandible angle (Heino and Hentunen, 2008), thus leading to functional improvement. In this study, however, the presence of mandibular osteocytes was not evaluated.

However, we can mention that in systemic sclerosis there is an increase in choline concentration due to the proliferation of inflammatory cells and thereby, an increase in myoelectric activity (Sener et al., 2019). What would explain the reduction in electromyographic activity? With AHSCT, there is a reduction in the number of 
inflammatory cells, thus improving the functional status of subjects with autoimmune disease (Menasché, 2018).

This pilot study had limitations. First the number of patients is very low. Second the method of SENIAM may be burdened with a larger measurement error. Third the study does not present a comparative set of healthy individuals to determine any standard results. Fourth limitation would be the evaluation period of the stomatognathic system after autologous stem cell transplantation (i.e. two months), may have been insufficient. A longer period of evaluation after therapy would have probably resulted in significant data.

\section{Conclusion}

The results suggest that patients with systemic sclerosis treated with AHSCT may present improvements in electromyographic activity of the masticatory muscles, especially observed in the dental clenching in maximal voluntary contraction of the left temporal muscle. Therefore, this study opens up great horizons in many areas of research to better understand the functional behavior of the stomatognathic system in subjects with systemic sclerosis undergoing AHSCT.

\section{References}

Bergamasco, A., Hartmann, N., Wallace, L., Verpillat, P. (2019) Epidemiology of systemic sclerosis and systemic sclerosis-associated interstitial lung disease. Clin. Epidemiol. 11, 257-273.

Blank, N., Lisenko, K., Pavel, P., Bruckner, T., Ho, A. D., Wuchter, P. (2016) Low-dose cyclophosphamide effectively mobilizes peripheral blood stem cells in patients with autoimmune disease. Eur. J. Haematol. 97, 78-82.

Burt, R. K., Shah, S. J., Dill, K., Grant, T., Gheorghiade, M., Schroeder, J., Craig, R., Hirano, I., Marshall, K., Ruderman, E., Jovanovic, B., Milanetti, F., Jain, S., Boyce, K., Morgan, A., Carr, J., Barr, W. (2011) Autologous non-myeloablative haemopoietic stem-cell transplantation compared with pulse cyclophosphamide once per month for systemic sclerosis (ASSIST): an open-label, randomised phase 2 trial. Lancet 378, 498-506.

Burt, R. K., Oliveira, M. C., Shah, S. J., Moraes, D. A., Simoes, B., Gheorghiade, M., Schroeder, J., Ruderman, E., Farge, D., Chai, Z. J., Marjanovic, Z., Jain, S., Morgan, A., Milanetti, F., Han, X., Jovanovic, B., Helenowski, I. B., Voltarelli, J. (2013) Cardiac involvement and treatment-related mortality after nonmyeloablative haemopoietic stem-cell transplantation with unselected autologous peripheral blood for patients with systemic sclerosis: a retrospective analysis. Lancet 381, 1116-1124.

Butt, S. A., Jeppesen, J. L., Fuchs, C., Mogensen, M., Engelhart, M., Torp-Pedersen, C., Gislason, G. H., Jacobsen, S., Andersson, C. (2018) Trends in incidence, mortality, and causes of death associated with systemic sclerosis in Denmark between 1995 and 2015: a nationwide cohort study. BMC Rheumatol. 2, 36.

Cecílio, F. A., Regalo, S. C., Palinkas, M., Issa, J. P., Siéssere, S., Hallak, J. E., Machado-de-Sousa, J. P., Semprini, M. (2010) Ageing and surface EMG activity patterns of masticatory muscles. J. Oral Rehabil. 37, 248-255.

Costa-Pereira, K. R., Guimarães, A. L., Moraes, D. A., Dias, J. B. E., Garcia, J. T., de Oliveira-Cardoso, E. A., Zombrilli, A., Leopoldo, V., Costa, T. M., Simões, B. P., Oliveira, M. C. (2019) Hematopoietic stem cell transplantation improves functional outcomes of systemic sclerosis patients. J. Clin. Rheumatol. (publish ahead of print) 
Crincoli, V., Fatone, L., Fanelli, M., Rotolo, R. P., Chialà, A., Favia, G., Lapadula, G. (2016) Orofacial manifestations and temporomandibular disorders of systemic scleroderma: an observational study. Int. J. Mol. Sci. 17, 1189.

Dimeo, F., Schwartz, S., Fietz, T., Wanjura, T., Böning, D., Thiel, E. (2003) Effects of endurance training on the physical performance of patients with hematological malignancies during chemotherapy. Support. Care Cancer 11, 623-628.

Di Palma, E., Tepedino, M., Chimenti, C., Tartaglia, G. M., Sforza, C. (2017) Effects of the functional orthopaedic therapy on masticatory muscles activity. J. Clin. Exp. Dent. 9, e886-e891.

Giudice, A. L., Brewer, I., Leonardi, R., Roberts, N., Bagnato, G. (2018) Pain threshold and temporomandibular function in systemic sclerosis: comparison with psoriatic arthritis. Clin. Rheumatol. 37, 1861-1867.

Hausmanowa-Petrusewicz, I., Jabłońska, S., Błaszczyk, M., Matz, B. (1982) Electromyographic findings in various forms of progressive systemic sclerosis. Arthritis Rheum. 25, 61-65.

Heino, T. J., Hentunen, T. A. (2008) Differentiation of osteoblasts and osteocytes from mesenchymal stem cells. Curr. Stem Cell Res. Ther. 3, 131-145.

Hermens, H. J., Freriks, B., Disselhorst-Klug, C., Rau, G. (2000) Development of recommendations for SEMG sensors and sensor placement procedures. J. Electromyogr. Kinesiol. 10, 361-374.

Hwang, K., Kim, Y. J., Chung, I. H., Lee, S. I. (2001) Deep middle masseteric artery (dMMA) attributed to hemorrhage in resection of masseter muscle and mandibular angle. J. Craniofac. Surg. 12, 381-385.

lordache, C., Antohe, M. E., Chirieac, R., Ancuța, E., Țănculescu, O., Ancuța, C. (2019) Volumetric cone beam computed tomography for the assessment of oral manifestations in systemic sclerosis: data from an EUSTAR cohort. J. Clin. Med. 8, 1620.

Johnson, S. R. (2015) New ACR EULAR guidelines for systemic sclerosis classification. Curr. Rheumatol. Rep. $17,32$.

Khodayari, S., Khodayari, H., Amiri, A. Z., Eslami, M., Farhud, D., Hescheler, J., Nayernia, K. (2019) Inflammatory microenvironment of acute myocardial infarction prevents regeneration of heart with stem cells therapy. Cell. Physiol. Biochem. 53, 887-909.

Lee, J. H., Kim, H. S., Yun, D. H., Chon, J., Han, Y. J., Yoo, S. D., Kim, D. H., Lee, S. A., Joo, H. I., Park, J. S., Kim, J. C., Soh, Y. (2016) The relationship between tongue pressure and oral dysphagia in stroke patients. Ann. Rehabil. Med. 40, 620-628.

Maiti, S. K., Shivakumar, M. U., Mohan, D., Kumar, N., Singh, K. P. (2018) Mesenchymal stem cells of different origin-seeded bioceramic construct in regeneration of bone defect in rabbit. Tissue Eng. Regen. Med. 15, 477-492

McNeil, C. J., Allen, M. D., Olympico, E., Shoemaker, J. K., Rice, C. L. (2015) Blood flow and muscle oxygenation during low, moderate, and maximal sustained isometric contractions. Am. J. Physiol. Regul. Integr. Comp. Physiol. 309, R475-R481.

Menasché, P. (2018) Cell therapy trials for heart regeneration - Lessons learned and future directions. Nat. Rev. Cardiol. 15, 659-671.

Mendonça, P., Taulaigo, A. V., Caetano, A., Moraes-Fontes, M. F. (2019) Mandibular resorption and vocal cord paralysis: a catastrophic form of systemic sclerosis. BMJ Case Rep. 12, e228262.

Miniati, I., Guiducci, S., Conforti, M. L., Rogai, V., Fiori, G., Cinelli, M., Saccardi, R., Guidi, S., Bosi, A., Tyndall, A., Matucci-Cerinic, M. (2009) Autologous stem cell transplantation improves microcirculation in systemic sclerosis. Ann. Rheum. Dis. 68, 94-98.

Mirsaeidi, M., Barletta, P., Glassberg, M. K. (2019) Systemic sclerosis associated interstitial lung disease: new directions in disease management. Front. Med. (Lausanne) 6, 248.

Perković, D., Petrić, M., Božić, I., Borić, K., Marasović Krstulović, D., Radić, M., Martinović Kaliterna, D. (2020) 
Low dose intravenous immunoglobulin in addition to cyclophosphamide in systemic sclerosis: single centre experience. Wien. Klin. Wochenschr. (publish ahead of print)

Plowman, E. K., Bijangi-Vishehsaraei, K., Halum, S., Cates, D., Hanenberg, H., Domer, A. S., Nolta, J. A., Belafsky, P. C. (2014) Autologous myoblasts attenuate atrophy and improve tongue force in a denervated tongue model: a pilot study. Laryngoscope 124, E20-E26.

Sener, U., Martinez-Thompson, J., Laughlin, R. S., Dimberg, E. L., Rubin, D. I. (2019) Needle electromyography and histopathologic correlation in myopathies. Muscle Nerve 59, 315-320.

Sierra-Sepúlveda, A., Esquinca-González, A., Benavides-Suárez, S. A., Sordo-Lima, D. E., Caballero-Islas, A. E., Cabral-Castañeda, A. R., Rodríguez-Reyna, T. S. (2019) Systemic sclerosis pathogenesis and emerging therapies, beyond the fibroblast. Biomed Res. Int. 2019, 4569826.

Siéssere, S., de Albuquerque Lima, N., Semprini, M., de Sousa, L. G., Paulo Mardegan Issa, J., Aparecida Caldeira Monteiro, S., Cecílio Hallak Regalo, S. (2009) Masticatory process in individuals with maxillary and mandibular osteoporosis: electromyographic analysis. Osteoporos. Int. 20, 1847-1851.

Sobolewski, P., Maślińska, M., Wieczorek, M., Łagun, Z., Malewska, A., Roszkiewicz, M., Nitskovich, R., Szymańska, E., Walecka, I. (2019) Systemic sclerosis - Multidisciplinary disease: Clinical features and treatment. Reumatologia 57, 221-233.

Sullivan, K. M., Goldmuntz, E. A., Keyes-Elstein, L., McSweeney, P. A., Pinckney, A., Welch, B., Mayes, M. D., Nash, R. A., Crofford, L. J., Eggleston, B., Castina, S., Griffith, L. M., Goldstein, J. S., Wallace, D., Craciunescu, O., Khanna, D., Folz, R. J., Goldin, J., St Clair, E. W., Seibold, J. R., Phillips, K., Mineishi, S., Simms, R. W., Ballen, K., Wener, M. H., Georges, G. E., Heimfeld, S., Hosing, C., Forman, S., Kafaja, S., Silver, R. M., Griffing, L., Storek, J., LeClercq, S., Brasington, R., Csuka, M. E., Bredeson, C., KeeverTaylor, C., Domsic, R. T., Kahaleh, M. B., Medsger, T., Furst, D. E.; SCOT Study Investigators (2018) Myeloablative autologous stem-cell transplantation for severe scleroderma. N. Engl. J. Med. 378, 35-47.

van Laar, J. M., Farge, D., Sont, J. K., Naraghi, K., Marjanovic, Z., Larghero, J., Schuerwegh, A. J., Marijt, E. W., Vonk, M. C., Schattenberg, A. V., Matucci-Cerinic, M., Voskuyl, A. E., van de Loosdrecht, A. A., Daikeler, T., Kötter, I., Schmalzing, M., Martin, T., Lioure, B., Weiner, S. M., Kreuter, A., Deligny, C., Durand, J. M., Emery, P., Machold, K. P., Sarrot-Reynauld, F., Warnatz, K., Adoue, D. F., Constans, J., Tony, H. P., Del Papa, N., Fassas, A., Himsel, A., Launay, D., Lo Monaco, A., Philippe, P., Quéré, I., Rich, É., Westhovens, R., Griffiths, B., Saccardi, R., van den Hoogen, F. H., Fibbe, W. E., Socié, G., Gratwohl, A., Tyndall, A.; EBMT/EULAR Scleroderma Study Group (2014) Autologous hematopoietic stem cell transplantation vs intravenous pulse cyclophosphamide in diffuse cutaneous systemic sclerosis: a randomized clinical trial. JAMA 311, 2490-2498.

van Leeuwen, N. M., Boonstra, M., Huizinga, T. W. J., Kaptein, A. A., de Vries-Bouwstra, J. K. (2020) Illness perceptions, risk perceptions and worries in patients with early systemic sclerosis: a focus group study. Musculoskeletal Care 18, 177-186.

Wiskemann, J., Huber, G. (2008) Physical exercise as adjuvant therapy for patients undergoing hematopoietic stem cell transplantation. Bone Marrow Transplant. 41, 321-329. 